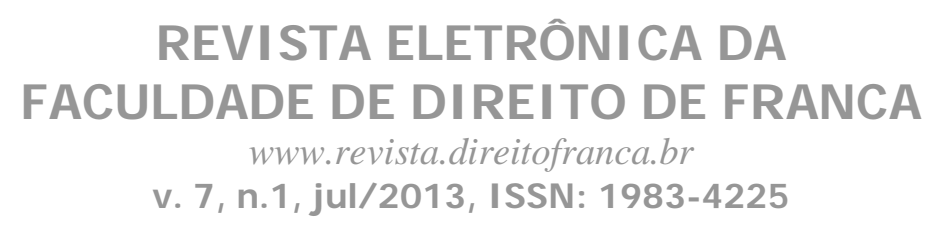

\title{
BREVES CONSIDERAÇÕES SOBRE A PROTEÇÃO DO IDOSO NO ÂMBITO DA FAMÍLIA
}

Ana Claudia Paes Witzel

http://buscatextual.cnpq.br/buscatextual/visualizacv.do?id=K4499003H1

Maria Amália De Figueiredo Pereira Alvarenga

http://buscatextual.cnpq.br/buscatextual/visualizacv.do?id=K4771856T0

\begin{abstract}
Resumo: Este artigo, partindo da análise que a população brasileira está envelhecendo, se propõe a estudar o idoso. Para isso, indica o Direito como um instrumento de proteção aos idosos por meio de diversos diplomas legais. Como a Constituição Federal de 1988 se preocupou em trazer no seu texto novos sujeitos de direito, no momento seguinte a promulgação da nova Constituição brasileira houve a proliferação de inúmeros microssistemas legislativos, entre os quais se insere o Estatuto do Idoso. Ressaltando que os microssistemas abrangem matérias de diversos ramos do direito, tanto do público como do privado, inclusive de matéria familiar, chega-se ao estudo de como a proteção do idoso no âmbito do Direito de Família é fundamental, já que a família é a menor célula da sociedade e os idosos são integrantes da família.
\end{abstract}

Palavras-chave: Idoso; Proteção constitucional; Estatuto do Idoso; Direito de Família.

The elderly protection within the family

Abstract: This article, starting from the analysis that the Brazilian population is aging, proposes to study the elderly. To do so, it indicates the Law as an instrument to protect the elderly through various legal norms. As the 1988 Constitution bothered to bring in its text new subjects of Law, right after the promulgation of the new Brazilian Constitution there was the proliferation of numerous legislative microsystems, among which the Elderly Statute is inserted. Pointing out that the microsystems cover subjects from different branches of Law, both public and private, including family matters, one comes to the study of how the protection of the elderly within the family law is essential, since the family is the smallest cell of society and the elderly are family members.

Keywords: elderly; constitutional protection, the Elderly Statute, Family Law.

\section{INTRODUÇÃO}

O presente trabalho, valendo-se principalmente do método dedutivo e de maneira complementar o método empírico, objetiva estudar a proteção do idoso no contexto familiar.

O tema revela-se de extrema importância, tanto pelo fato de ser pouco explorado, como em razão do constante aumento da população idosa no Brasil e no mundo. Deste modo, a sociedade e sobretudo a família precisa se preparar para dar ao idoso o tratamento adequado e que lhe é garantido pela Constituição e perante o diploma específico do Estatuto do Idoso. 


\section{REVI STA ELETRÔNI CA DA FACULDADE DE DI REITO DE FRANCA \\ www.revista.direitofranca.br \\ v. 7, n.1, jul/ 2013, ISSN: 1983-4225}

Assim, serão analisadas as obrigações que os filhos devem ter perante seus pais idosos, desde a já indiscutível obrigação alimentar até o dever de cuidado e afeto que, cada vez mais, está sendo valorizado em nossos Tribunais.

\section{A POPULAÇÃO IDOSA NO BRASIL}

A concepção do que é uma pessoa idosa varia de tempos em tempos, acompanhando as transformações culturais da sociedade. No passado, quando as condições humanas de saúde, higiene e saneamento básico não permitiam que a expectativa de vida de uma pessoa ultrapassasse a faixa etária dos quarenta anos era possível, subjetivamente, uma pessoa idosa era aquela que alcançasse e ultrapassasse a idade média de vida das pessoas de um determinado local ou região. Hoje, é fato que a população idosa está aumentando mundialmente e o processo de envelhecimento é irreversível.

Como causas diretas do envelhecimento populacional, dentre outros fatores, pode-se verificar a diminuição das taxas de natalidade como consequencia da disseminação de métodos contraceptivos e da entrada definitiva da mulher no mercado de trabalho. Também observa-se a diminuição das taxas de mortalidade e aumento da expectativa de vida como frutos dos avanços da medicina.

Em razão das diversas condições de vida da população em geral, cada país define o critério que utilizará para definir juridicamente o conceito de idoso. No Brasil, utiliza-se o critério etário para classificar juridicamente uma pessoa como idosa, sendo desnecessário o uso de qualquer outro critério subjetivo para tal classificação. ${ }^{1}$ Assim, o art. $1^{\circ}$ do Estatuto do Idoso (Lei $\mathrm{n}^{\circ} 10.741$ de 2003) expressa que tal regulamento destina-se "às pessoas com idade igual ou superior a sessenta anos”. A mesma idade expressa a Política Nacional do Idoso (lei $n^{\circ} 8.842$ de 1994).

Entretanto, ainda existe certa dificuldade de padronização, pois alguns direitos específicos são concedidos para idosos com uma idade específica, como é o caso da gratuidade dos transportes coletivos, que é concedida aos idosos maiores de sessenta e cinco anos (art. 39 do Estatuto do Idoso e art. 230, §2º da Constituição Federal).

\footnotetext{
${ }^{1}$ Cf. RODRIGUES, Oswaldo Peregrina. A pessoa idosa e sua convivência em família. In:PEREIRA, Rodrigo da Cunha; PEREIRA, Tânia da Silva (Coord.). A ética da convivência familiar e sua efetividade no cotidiano dos tribunais. Rio de Janeiro: Forense, 2006. p. 396.
} 


\section{REVI STA ELETRÔNI CA DA FACULDADE DE DI REITO DE FRANCA \\ www.revista.direitofranca.br \\ v. 7, n.1, jul/ 2013, ISSN: 1983-4225}

Ademais, ressalta-se que com o aumento da expectativa de vida da população o critério etário não é um padrão permanente, pois conquanto que atualmente considera-se idosa uma pessoa de sessenta anos, é certo que nesta idade inúmeras pessoas ainda estão no auge da atividade profissional e sequer se consideram como idosos. Segundo a visão médica, o processo de envelhecimento é um processo natural que ocorre no ser humano uma redução da reserva funcional sem comprometer, necessariamente, as atividades normais do dia-a-dia. ${ }^{2}$

De acordo com a ONU, o número de pessoas com mais de 60 anos no mundo em 2050 deve alcançar dois bilhões de pessoas, sendo que na maior parte dos países, o número de idosos com mais de 80 anos deve quadruplicar. ${ }^{3}$

Dados indicam que no Brasil, entre 1998 e 2008, a proporção de idosos aumentou de 8,8\% para 11,1\%. Aponta a projeção do IBGE para os próximos vinte anos uma população idosa ultrapassando os 30 milhões de pessoas, o que deverá representar em 2050 cerca de 19\% da população total. ${ }^{4}$ Dentro desses parâmetros, considera-se o processo de envelhecimento da população brasileira como um fenômeno irreversível.

Por outro lado, um estudo organizado pela Organização Mundial de Saúde (OMS) aponta outros dados, prevendo para o ano de 2025 uma população brasileira com mais de 34 milhões de idosos, o que colocaria o Brasil na sexta posição de população mais envelhecida do mundo. ${ }^{5}$

Em face de tais mudanças, não se pode ignorar a questão da violência, abandono, negligência ou maus tratos físicos e psicológicos contra os idosos. Há uma dificuldade relativa à coleta de dados estatísticos sobre o tema em virtude de a maioria dos casos ocorrerem dentro do ambiente familiar e em razão do idoso não ter coragem de denunciar a agressão ou temer pela represália do agressor, os dados existentes não conseguem demonstrar fielmente a realidade desta questão. ${ }^{6}$

\footnotetext{
${ }^{2}$ Cf. FILHO, Wilson Jacob. Cuidar do idoso é desafio para a medicina do século 21. Ser médico, São Paulo, n. 61, p. 28-31, nov./dez. 2012. p. 28.

${ }^{3}$ Cf. A ONU e as pessoas idosas. Disponível em: < http://www.onu.org.br/a-onu-em-acao/a-onu-em-acao/a-onue-as-pessoas-idosas/>. Acesso em 27 mar. 2013.

${ }^{4}$ Cf. BRAGA, Pérola Melissa Vianna. Curso de Direito do Idoso. São Paulo: Atlas, 2011. p. 20.

${ }^{5}$ Cf. CABRAL, Sérgio. Os direitos da terceira idade, p. 99 apud PERES, Ana Paula Ariston Barion. Proteção aos idosos. Curitiba: Juruá, 2011. p. 20

${ }^{6}$ Cf. JUSSANA DE SOUSA, Danúbia et al . Maus-tratos contra idosos: atualização dos estudos brasileiros. Rev. Bras. Geriatr. Gerontol., Rio de Janeiro, v. 13, n. 2, ago. 2010 . Disponível em $<$ http://revista.unati.uerj.br/scielo.php?script=sci_arttext\&pid=S1809-98232010000200016\&lng=pt\&nrm=iso $>$. Acessos em 26 mar. 2013.
} 


\section{REVI STA ELETRÔNI CA DA FACULDADE DE DI REITO DE FRANCA \\ www.revista.direitofranca.br \\ v. 7, n.1, jul/ 2013, ISSN: 1983-4225}

Com relação a esses dados, "estudos nacionais apontam para a prevalência da violência doméstica. Pesquisa realizada em 2007 demonstrou que, dos 18 milhões de idosos brasileiros, $12 \%$ já sofreram algum tipo de maus-tratos, dos quais $54 \%$ foram causadas pelos filhos."7

Em recente pesquisa realizada na Central do Idoso de Brasília entre janeiro a agosto de 2012, conclui-se que são as idosas entre a faixa etária dos 66 aos 75 quem mais buscou ajuda contra casos de violência tanto física quanto psíquica por parte, principalmente, dos filhos do sexo masculino. ${ }^{8}$

Já no estado do Rio Grande do Sul, o Conselho Estadual do Idoso divulgou que em 2011 que 84\% dos casos de violência ocorrem em casa, sendo que em 58\% dos casos os agressores são os próprios filhos. ${ }^{9}$

Portanto, é de fundamental importância a constatação de que com essa substancial mudança do perfil da população brasileira, a sociedade terá que se adequar para que cada vez mais os direitos dos idosos sejam efetivados, garantindo sua proteção. Da mesma forma, a família como a menor forma de organização social existente e como a principal responsável pelo idoso terá o desafio de priorizar o melhor interesse do idoso, prestar assistência material, moral e afetiva e tratá-lo com respeito e dignidade. ${ }^{10}$

\section{PROTEÇÃO CONSTITUCIONAL E TUTELA INTERNACIONAL}

O processo de envelhecimento é natural do ser humano e constitui um direito humano fundamental. A proteção constitucional é essencial, já que a sociedade enxerga a velhice de forma preconceituosa e excludente, ao vê-la como uma etapa da vida de decadência que inicia com a diminuição até a cessação total dos atos laborativos. E, diante de tal visão negativa da velhice, como consequência vislumbra-se a exclusão do idoso perante a sociedade

\footnotetext{
${ }^{7}$ FALEIROS, Vicente de Paula. Violência contra a pessoa idosa - ocorrências, vítimas e agressores. Brasília: Universa; 2007. p. 394 apud JUSSANA DE SOUSA, Danúbia et al . Maus-tratos contra idosos: atualização dos estudos brasileiros. Rev. Bras. Geriatr. Gerontol., Rio de Janeiro, v. 13, n. 2, ago. 2010 . Disponível em $<$ http://revista.unati.uerj.br/scielo.php?script=sci_arttext\&pid=S1809-98232010000200016\&lng=pt\&nrm=iso $>$. Acessos em 26 mar. 2013.

8 Cf. Central do idoso divulga estatísticas de violência contra idosos no DF. Disponível em: $<$ http://www.tjdft.jus.br/institucional/imprensa/noticias/2012/setembro/central-do-idoso-divulga-estatisticas-deviolencia-contra-idosos-no-df > . Acesso em 26 mar. 2013.

9 Cf. Conselho divulga dados da violência contra os idosos. Disponível em: <http://www.sjdh.rs.gov.br/?model=conteudo\&menu=1\&id=285\&pg=>. Acesso em: 26 mar. 2013.

${ }^{10}$ Cf. BRAGA, Pérola Melissa Vianna, op. cit., p. 14.
} 


\section{REVI STA ELETRÔNI CA DA FACULDADE DE DI REITO DE FRANCA \\ www.revista.direitofranca.br \\ v. 7, n.1, jul/ 2013, ISSN: 1983-4225}

e também na família. No Brasil, a proteção a uma velhice digna só foi tutelado constitucionalmente em 1988.

Genericamente, observa-se que a Constituição Federal possui como objetivo fundamental da República a vedação de qualquer discriminação em razão da idade, o que se extrai de uma leitura extensiva do seu art. $3^{\circ}$, IV. Com relação à dignidade humana, identifica-se “a existência do princípio do melhor interesse do idoso na Constituição Federal como consectário natural da cláusula geral de tutela da pessoa humana, que atua como fonte da proteção integral que é devida ao idoso"11. Além disso, vislumbra-se como tutela protetiva específica aos idosos nos arts. 229 e 230, do capítulo destinado especialmente à família, criança, adolescente, jovem e idoso.

Segundo o art. 229 da Constituição Federal, “os pais têm o dever de assistir, criar e educar os filhos menores, e os filhos maiores têm o dever de ajudar e amparar os pais na velhice, carência ou enfermidade.” Vislumbra-se, desta forma, o princípio da igualdade, já que a mesma tutela protetiva conferida às crianças e aos adolescentes foi concedida as pessoas idosas em virtude de ambos representarem um segmento da população considerado como vulneráveis em virtude da fragilidade oriunda da idade dos dois extremos da vida, fatores estes biologicamente comprovados como causadores de vulnerabilidade. ${ }^{12}$ No mais, tal artigo expressa implicitamente o princípio de respeito recíproco entre pais e filhos.

Outrossim, a proteção constitucional da pessoa idosa no âmbito da família objetiva concretizar a dignidade da pessoa humana, já que "a vulnerabilidade, por representar uma ameaça latente à dignidade da pessoa humana, não passou despercebida pelo direito constitucional, figurando, às vezes, no âmago das normas constitucionais.”13 Neste sentido, o art. 230 da Magna Carta traz que "a família, a sociedade e o Estado têm o dever de amparar as pessoas idosas, assegurando sua participação na comunidade, defendendo sua dignidade e bem-estar e garantindo-lhes o direito à vida.”

11 BARBOZA, Heloisa Helena. O princípio do melhor interesse do idoso. In: PEREIRA, Tânia da Silva; OLIVEIRA, Guilherme de (coords.). O cuidado como valor jurídico. Rio de Janeiro: Forense, 2008, p. 57. apud GAMA, Guilherme Calmon Nogueira da. Pessoa idosa no direito de família. Disponível em: <http://civilistica.com/wp-content/uploads/2013/01/Guilherme-Calmonciv.a2.n1.2013.pdf>.Acesso em: $20 \mathrm{mar}$. 2012.

${ }^{12}$ Cf. PERES, Ana Paula Ariston Barion, op. cit., p. 23.

${ }^{13}$ VALLET, Elisabeth. La vulnérabilité et le droit constitutionnel. In: Vulnérabilité et droit. Le développement de la vulnérabilité et ses enjeux en droit. Grenoble: PUG, 2000. p. 64 apud PERES, Ana Paula Ariston, op. cit., p. 47. 


\section{REVI STA ELETRÔNI CA DA FACULDADE DE DI REITO DE FRANCA \\ www.revista.direitofranca.br \\ v. 7, n.1, jul/ 2013, ISSN: 1983-4225}

No mais, não se desconhece os demais artigos que preveem, indiretamente, a tutela do idoso, como no caso da assistência social e previdência social. Todavia, não é o objetivo desta pesquisa se aprofundar em toda a tutela do idoso, mas sim naquela perante a família.

Os idosos não foram esquecidos pelo constituinte. Ao contrário, vários dispositivos mencionam a velhice como objeto de direitos específicos, como do direito previdenciário (art. 201, I), do direito assistencial (art. 203, I), mas há dois dispositivos que merecem referência especial, porque o objeto de consideração é a pessoa em sua terceira idade.Assim é que no art. 230 estatui que a família, a sociedade e o Estado têm o dever de amparar as pessoas idosas, assegurando sua participação na comunidade, defendendo sua dignidade e bem-estar e garantindo-lhes o direito à vida, de preferência mediante programas executados no recesso do lar, garantindo-se, ainda, o beneficio de um salário mínimo mensal ao idoso que comprove não possuir meios de prover a própria manutenção ou de tê-la provida por família, conforme dispuser a lei (art. 203, V), e, aos maiores de sessenta e cinco anos, independentes de condição social, é garantida a gratuidade dos transportes urbanos. ${ }^{14}$

Como o aumento da população idosa se constitui em um problema social mundialmente relevante, existem tutelas internacionais garantindo direitos aos idosos. A Declaração Universal dos Direitos do Homem de 1948 trata da proteção à velhice em seu art. $25^{15}$ e a Convenção Americana sobre Direitos Humanos de 1978, em seu art. $1^{\circ}$, estabelece, entre outros temas, que nenhuma pessoa será discriminada em razão da idade. ${ }^{16}$ Em 1988 , foi adotado um protocolo adicional à Convenção Americana de Direitos Humanos, que passou a vigorar um ano após, denominado Protocolo de San Salvador cujo art. 17 trouxe recomendações aos Estados signatários sobre medidas necessárias para atender às pessoas idosas. $^{17}$

Além disso, no ano de 1991, foi elaborado os “Princípios das Nações Unidas para as Pessoas Idosas” ${ }^{18}$ a fim de ampliar os direitos e garantias dos idosos da Declaração Universal dos Direitos do Homem e de outras declarações e tratados internacionais, já que constatavamse que cada vez mais as pessoas estavam envelhecendo no mundo e era necessária uma tutela

\footnotetext{
${ }^{14}$ SILVA, José Afonso da. Curso de direito constitucional positivo. 18 ${ }^{\mathrm{a}}$ ed. São Paulo: Malheiros, 2000. p. 824825.

${ }^{15}$ Toda pessoa tem direito a um padrão de vida capaz de assegurar a si e a sua família saúde e bem-estar, inclusive alimentação, vestuário, habitação, cuidados médicos e os serviços sociais indispensáveis, e direito à segurança, em caso de desemprego, doença, invalidez, viuvez, velhice ou outros casos de perda dos meios de subsistência em circunstâncias fora de seu controle.

${ }^{16}$ Cf. DINIZ, Paula Fernanda, op. cit., p.51-53. passim.

${ }^{17}$ Cf. ALCÂNTARA, Alexandre de Oliveira. O direito fundamental à velhice digna: limites e possibilidades de sua efetivação. 2007. 114f. Dissertação (Mestrado Direito) -Universidade de Fortaleza, Fortaleza, 2007. p. 31.

${ }^{18} \mathrm{Cf}$. A ONU e as pessoas idosas, op. cit., nota 46.
} 


\section{REVI STA ELETRÔNI CA DA FACULDADE DE DI REITO DE FRANCA \\ www.revista.direitofranca.br \\ v. 7, n.1, jul/ 2013, ISSN: 1983-4225}

internacional mais detalhada. Entre o conjunto enumerado de dezoito princípios, ficou estabelecido que "os idosos devem beneficiar dos cuidados e da proteção da família e da comunidade em conformidade com o sistema de valores culturais de cada sociedade”, princípio este que em muito se assemelha com o disposto no art. 230 da Constituição Federal brasileira.

Também, nos anos de 1982 e 2002 aconteceram, respectivamente, a primeira e a segunda Assembleia Mundial das Nações Unidas sobre o Envelhecimento. Na segunda Assembleia foi elaborado um documento denominado "Plano de Ação Internacional sobre o Envelhecimento”, o qual consistia em um plano para mudança de atitudes por parte de diversos setores para a implementação efetiva dos direitos dos idosos. Houve a participação do Brasil em ambas as Assembleias bem como a assinatura dos documentos elaborados o que obriga sua incorporação no país. ${ }^{19}$

Por fim, ressalta-se que além da Constituição brasileira, atualmente no mundo outros onze países tutelam no corpo de seu texto o idoso, sendo esses países a China, Cuba, Espanha, Guiné-Bissau, Itália, México, Peru, Portugal, Suíça, Uruguai e Venezuela. Entre estas, além da brasileira, somente a Constituição da China destaca a importância da família para o cuidado dos idosos. ${ }^{20}$ Trata-se de um número ínfimo de constituições já que o significativo aumento da população idosa mundialmente gera uma relevante preocupação sobre seus direitos e dignidade.

\section{PROTEÇÃO PERANTE O ESTATUTO DO IDOSO}

O Estatuto do Idoso (Lei 10.741/03) se insere no contexto da promulgação da Constituição Federal de 1988 e a proliferação dos microssistemas, ou seja, diplomas legais multidisciplinares que consagram inúmeros direitos tanto do direito público como do privado às pessoas maiores de sessenta anos. Logo, justifica-se a proteção à pessoa idosa por meio de uma lei específica que tutela determinadas situações que não estavam expressamente previstos

${ }^{19}$ Cf. ALCÂNTARA, Alexandre de Oliveira, op. cit., p. 27.

${ }^{20}$ Cf. RAMOS, Paulo Roberto Barbosa. A velhice na Constituição. Disponível em: $<$ http://periodicos.ufsc.br/index.php/sequencia/article/view/15513/14069>. Acesso em: 03 abr. 2013. 


\section{REVI STA ELETRÔNI CA DA FACULDADE DE DI REITO DE FRANCA \\ www.revista.direitofranca.br \\ v. 7, n.1, jul/ 2013, ISSN: 1983-4225}

nas normas infraconstitucionais, mas que se mostravam fundamentais perante a nova ordem constitucional. $^{21}$

Ressalta-se, contudo, que antes da Lei 10.741/03 ter sido aprovada, existia desde 1994 a Política Nacional do Idoso (Lei 8.842/94), o qual buscava dar o mínimo de regulamentação ao diploma constitucional, mas se mostrou insuficiente para proporcionar uma tutela efetiva aos idosos. $^{22}$

Embora o Estatuto do Idoso seja considerado um grande avanço e um marco no direito dos idosos, por consolidar o direito dos idosos antes esparsos em diversas legislações, muitas críticas apontam que ele na realidade, não constituiu em grandes inovações, mas tão somente reproduziu tutelas já previstas em outras legislações, como na Política Nacional do Idoso e no Código Civil. Por outro ponto de vista, o maior mérito do Estatuto do Idoso se deu justamente pelo fato de unificar todas as legislações existentes vez que facilitou o acesso às pessoas idosas acerca de seus direitos.

Ademais, pode-se ver o Estatuto do Idoso como um diploma normativo que veio instituir o princípio da igualdade entre os polos opostos da vida ${ }^{23}$, ou seja, entre a infância e a velhice haja vista que já existia a proteção às crianças e aos adolescentes por meio Estatuto da Criança e do Adolescente desde 1990 e somente no ano de 2003 que os idosos tiveram seus direitos garantidos através de um Estatuto.

Propriamente relativo aos principais direitos assegurados às pessoas idosas perante a novidade legislativa e de relevância para esse estudo, primeiramente necessário colocar em questão que o Estatuto do Idoso estabeleceu em seu art. $2^{\circ}$ os reflexos dos princípios constitucionais de valorização da pessoa humana:

Art. $2^{0} \mathrm{O}$ idoso goza de todos os direitos fundamentais inerentes à pessoa humana, sem prejuízo da proteção integral de que trata esta Lei, assegurando-se-lhe, por lei ou por outros meios, todas as oportunidades e facilidades, para preservação de sua saúde física e mental e seu aperfeiçoamento moral, intelectual, espiritual e social, em condições de liberdade e dignidade.

\footnotetext{
${ }^{21}$ Cf. OLIVEIRA, Maria Rita de Holanda Silva. Reflexos da constitucionalização nas relações de família. In: LOTUFO, Renan. Direito civil constitucional: caderno 3. São Paulo: Malheiros, 2002. p.286.

${ }^{22}$ Cf. INDALENCIO, Maristela Nascimento. Estatuto do Idoso e direitos fundamentais: fundamentos da proteção da pessoa idosa no ordenamento jurídico brasileiro. 2007. 114f. Dissertação (Mestrado em Ciência Jurídica) -Universidade do Vale do Itajaí, Itajaí, 2007. p. 43.

${ }^{23}$ Cf. DIAS, Maria Berenice. Conversando sobre alimentos. Porto Alegra: Livraria do Advogado, 2006. p. 55
} 


\title{
REVI STA ELETRÔNI CA DA FACULDADE DE DI REITO DE FRANCA \\ www.revista.direitofranca.br \\ v. 7, n.1, jul/ 2013, ISSN: 1983-4225
}

Outrossim, destacam-se direitos específicos aos idosos, tais como o envelhecimento como um direito personalíssimo, as obrigações familiares e sociais, o respeito e o direito aos alimentos.

No que diz respeito ao envelhecimento como um direito personalíssimo, tem-se um direito inato, inerente ao ser humano, que dele não se pode abdicar ou transferir. Trata-se da própria vida, da liberdade, da honra, da própria dignidade humana. Explica Clodoaldo de Oliveira Queiroz:

\begin{abstract}
Dentre os direitos fundamentais dos idosos, o Estatuto estabelece em seu art. $8^{\circ}$ que o envelhecimento é um direito personalíssimo e sua proteção um direito social. Trata-se, conseqüentemente, de outra importante inovação legislativa porquanto insere no direito positivo mais um atributo aos direitos da personalidade, qual seja o direito de envelhecer com saúde e dignidade. ${ }^{24}$
\end{abstract}

Com relação ao direito de ser respeitado, o Estado e a sociedade devem assegurar a tutela deste importante dever, conforme assegura o art.10, $\S 2^{\circ}$ do Estatuto do Idoso, in verbis:

Art. 10. É obrigação do Estado e da sociedade, assegurar à pessoa idosa a liberdade, o respeito e a dignidade, como pessoa humana e sujeito de direitos civis, políticos, individuais e sociais, garantidos na Constituição e nas leis.

$\S 2^{\underline{0}} \mathrm{O}$ direito ao respeito consiste na inviolabilidade da integridade física, psíquica e moral, abrangendo a preservação da imagem, da identidade, da autonomia, de valores, idéias e crenças, dos espaços e dos objetos pessoais.

No mais, dispõe o $\S 3^{\circ}$ do mesmo artigo que “é dever de todos zelar pela dignidade do idoso, colocando-o a salvo de qualquer tratamento desumano, violento, aterrorizante, vexatório ou constrangedor.” Tal tutela vem trazer a este diploma legislativo o princípio da dignidade da pessoa humana.

Acrescenta-se que foi a partir da vigência do Estatuto do Idoso que começaram a surgir ação de alimentos dos idosos contra seus filhos, ainda que tal possibilidade já existisse pelo Código Civil, o que denota a importância deste instrumento legislativo para garantir o acesso dos idosos aos seus direitos. ${ }^{25}$

Portanto, o Estatuto do Idoso deve ser visto como uma norma de grande finalidade protetiva, definidora de direitos e garantias fundamentais que surgiu como fruto, nos dizeres de Paula Fernanda Diniz, da “necessidade de uma nova interpretação do Direito, que leve em

${ }^{24}$ QUEIROZ, Clodoaldo de Oliveira. Os direitos fundamentais dos idosos. Revista de Direito Privado, São Paulo, v. 25, p. 89-122, jan./mar. 2006. p. 97.

${ }^{25}$ Cf. BRAGA, Pérola Melissa Vianna, op. cit., p. 17. 


\section{REVI STA ELETRÔNI CA DA FACULDADE DE DI REITO DE FRANCA \\ www.revista.direitofranca.br \\ v. 7, n.1, jul/ 2013, ISSN: 1983-4225}

conta os direitos individuais constitucionalmente garantidos, a fim que os idosos sejam vistos como sujeitos de direitos a serem protegidos.”26

O estudo do Estatuto do Idoso revela-se relevante para o Direito de Família em função de sua característica multidisciplinar que exige um direito que olhe para diversas direções e por isso, repercute e influência no contexto familiar.

\section{O PRINCÍPIO DA SOLIDARIEDADE FAMILIAR E AS OBRIGAÇÕES ORIUNDAS DA RELAÇÃO DE PARENTESCO}

A relação entre pais e filhos, sob um ponto de vista jurídico, se refere às relações de parentesco em linha reta. Isto porque o parentesco sempre pressupõe em ascendentes que dão origem aos descendentes. Logo, os filhos são os descendentes que se originam por meio da filiação. Neste ponto, convém ressaltar que embora se trate de laços biológicos, os filhos adotivos também são considerados descendentes dos pais adotantes, em virtude de haver um desligamento do adotado dos laços da família consanguínea, bem como predominar o

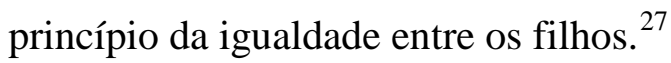

Ademais, quando se fala em relações de parentesco, sempre se pensa em direito de família quando na verdade poder-se-ia falar até mesmo em direito obrigacional, já que existem direitos e obrigações oriundos dessas relações, com fundamento no princípio da solidariedade familiar, expressos tanto explicitamente quanto implicitamente no texto constitucional e na legislação infraconstitucional.

O princípio da solidariedade familiar está diretamente ligado com a moral. Em virtude da prioridade dada à pessoa humana no texto constitucional, houve uma preocupação em atribuir o princípio da solidariedade familiar principalmente as pessoas mais frágeis e vulneráveis do contexto social, já que nitidamente são merecedores de maior proteção, como é o caso dos idosos, bem como das crianças e adolescentes. ${ }^{28}$ Desse sentido, explica com propriedade a estudiosa de direito dos idosos Pérola Melissa Vianna Braga: “além de nossa construção cultural e moral, sob o aspecto legal também a família antecede o poder público no

\footnotetext{
${ }^{26}$ DINIZ, Paula Fernanda, op. cit., p. 2.

${ }^{27}$ Cf. DIAS, Maria Berenice. Manual direito das famílias, op. cit., p. 348.

${ }^{28}$ Cf. GAMA, Guilherme Calmon Nogueira da. Alimentos entre parentes e direito processual civil. In: MADALENO, Rolf; PEREIRA, Rodrigo da Cunha (Org.). Direito de família: processo, teoria e prática. Rio de Janeiro: Forense, 2008. p. 229
} 


\section{REVI STA ELETRÔNI CA DA FACULDADE DE DI REITO DE FRANCA \\ www.revista.direitofranca.br \\ v. 7, n.1, jul/ 2013, ISSN: 1983-4225}

cuidado com o idoso. É a instituição do princípio da solidariedade, onde o Estado atua apenas de forma subsidiária.” 29

Neste diapasão, o idoso necessita de uma atenção redobrada já que, naturalmente pelo processo de envelhecer, pode necessitar de cuidados especiais ante a limitação do vigor físico além das demais limitações oriundas da idade avançada. Tal atenção e tal cuidado devem ser prestados pelos filhos ante os deveres oriundos do grau de parentesco. Nesta linha de raciocínio, leciona Guilherme Calmon Gama:

(...) o parentesco também é um vínculo jurídico estabelecido por lei, que assegura direitos e impõe deveres recíprocos. São elos que não se constituem nem se desfazem por atos de vontade. A espécie de parentesco, de maior ou menor proximidade dos parentes, dispõe reflexos jurídicos diversos, a depender do grau de intensidade da solidariedade familiar. De modo geral, atenta-se ao critério da proximidade: os parentes mais próximos são os primeiros a serem colocados. ${ }^{30}$

Por fim, destaca-se que a obrigação alimentar acompanha a ordem de vocação hereditária e com relação aos parentes em linha reta, e essa obrigação é infinita.

\subsection{DEVER DE ORDEM MATERIAL: A OBRIGAÇÃO ALIMENTAR EM FAVOR DO IDOSO}

Os alimentos compõem o rol dos direitos da personalidade já que estão relacionados à existência do ser humano e, deste modo, manifesta o direito à vida. Ademais, por meio de uma leitura constitucional, entende-se que os alimentos estão ligados ao princípio da solidariedade social e familiar.

A obrigação alimentar envolve o significado de valores, bens ou serviços destinados às necessidades existenciais da pessoa, fixando-se um valor suficiente a permitir que a pessoa viva de maneira digna. Com relação à questão alimentar em favor do idoso, tem-se como fonte principal da tutela prevista pelo Código Civil, já que o amparo no diploma normativo do Estatuto do Idoso estabelece que os alimentos serão prestados aos idosos na forma da lei civil,

\footnotetext{
${ }^{29}$ BRAGA, Pérola Melissa Vianna, op. cit., p. 14.

${ }^{30}$ GAMA, Guilherme Calmon Nogueira da, 2002, p. 107. apud DIAS, Maria Berenice. Manual de Direito das famílias. 8. ed. São Paulo: Editora Revista dos Tribunais, 2011.
} 


\section{REVI STA ELETRÔNI CA DA FACULDADE DE DI REITO DE FRANCA \\ www.revista.direitofranca.br \\ v. 7, n.1, jul/ 2013, ISSN: 1983-4225}

confirmando a possibilidade do ancião com dificuldades de promover sua subsistência pleitear alimentos. $^{31}$

Importante salientar que existe um requisito expresso no art. 1694, $\S 1^{\circ}$ do Código Civil, o qual dispõe que "os alimentos devem ser fixados na proporção das necessidades do reclamante e dos recursos da pessoa obrigada”. No mesmo sentido, o art. 1695 do Código Civil $^{32}$ fundamenta que prestação dos alimentos se rege de acordo com o binômio necessidade/possibilidade. Desta maneira, os alimentos devem ser fixados na proporção da necessidade do alimentado e de acordo com a possibilidade proveniente dos recursos do alimentante e não conforme a mera conveniência. Tal requisito existe para garantir a existência do alimentado sem causar nenhum prejuízo à subsistência do alimentante. É a existência desse requisito que faz com que a obrigação alimentar não faça coisa julgada material, mas tão somente coisa julgada formal, já que há possibilidade de revisão dos alimentos surge quando há um descompasso entre a necessidade do idoso e a possibilidade de seu filho em prestar alimentos.

Com relação às características dos alimentos e da obrigação alimentar, primeiramente observa-se o princípio da irrenunciabilidade, que é expresso pelo artigo 1707 do Código Civil. ${ }^{33}$ O direito do idoso em receber alimentos é irrenunciável, já que se trata de um direito de personalidade, e desta forma, conclui-se que sempre existe o direito de pleitear por alimentos, podendo ou não exercê-lo em consonância com suas necessidades.

Ademais, destaca-se o princípio da alternatividade disposto no artigo 1701 do

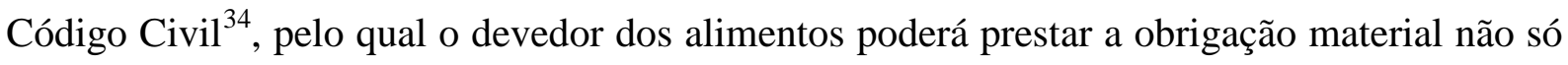
como pensão, mas também com outros bens essenciais à existência do alimentando, como moradia e vestuário.

De especial relevância é a análise que o Estatuto do Idoso conferiu, por meio de seu art. 12, um tratamento diferenciado ao estabelecer que a obrigação de prestar alimentos ao idoso é solidária. Trata-se de uma vantagem maior do que aos alimentos prestados às crianças

\footnotetext{
${ }^{31}$ Cf. FREITAS JÚNIOR, Roberto Mendes. Direitos e Garantias do Idoso: doutrina, jurisprudência e legislação. $2^{\circ}$ Ed. São Paulo: Atlas, 2011. p. 82.

${ }^{32}$ Art. 1.695. São devidos os alimentos quando quem os pretende não tem bens suficientes, nem pode prover, pelo seu trabalho, à própria mantença, e aquele, de quem se reclamam, pode fornecê-los, sem desfalque do necessário ao seu sustento.

${ }^{33}$ Art. 1.707. Pode o credor não exercer, porém lhe é vedado renunciar o direito a alimentos, sendo o respectivo crédito insuscetível de cessão, compensação ou penhora.

${ }^{34}$ Art. 1.701. A pessoa obrigada a suprir alimentos poderá pensionar o alimentando, ou dar-lhe hospedagem e sustento, sem prejuízo do dever de prestar o necessário à sua educação, quando menor.
} 


\section{REVI STA ELETRÔNI CA DA FACULDADE DE DI REITO DE FRANCA \\ www.revista.direitofranca.br \\ v. 7, n.1, jul/ 2013, ISSN: 1983-4225}

e adolescentes, já que o Estatuto da Criança e do Adolescente não prevê a obrigação alimentar solidária.

Destarte, em face do princípio da reciprocidade expresso no artigo 1696 do Código Civil $^{35}$, tem-se que a obrigação alimentar é um dever amplo já que recíproca entre pais e filhos. Tal princípio concretiza a ideia de solidariedade, já que em um primeiro momento são os filhos que precisam dos pais, mas em outra fase da vida, essa necessidade ou dependência se inverte. Neste caso, fundamenta a obrigação de prestar alimentos oriunda da relação de parentesco.

Polêmico é o questionamento acerca do pai que faltou com o filho na infância, deixando de lhe prestar alimentos, deveria ou não receber alimentos do filho. Para Pérola Melissa Vianna Braga ${ }^{36}$, não se deve pesar a análise em critérios subjetivos, já que tão somente deve ser observado o binômio necessidade/possibilidade, até mesmo porque, o Código Civil de 1916 tutelava o critério subjetivo no antigo texto do no artigo 399, parágrafo único e tal tutela foi suprimida pelo Código Civil de 2002 o que vem a corroborar com sua tese.

De modo contrário, a jurisprudência se posiciona confirmando o princípio da reciprocidade, arguindo que não se pode sujeitar o filho a ser alimentante do pai que na infância lhe rejeitou, de modo que o pai só terá direitos de receber alimentos se ajudou o filho em sua formação, fornecendo-lhe aquilo que era necessário para seu crescimento e sustento digno. ${ }^{37}$ Nesse sentido:

ALIMENTOS. SOLIDARIEDADE ALIMENTAR. DESCUMPRIMENTO DOS DEVERES INERENTES AO PODER FAMILIAR. É descabido o pedido de alimentos, com fundamento no dever de solidariedade, pelo genitor que nunca cumpriu com os deveres inerentes ao poder familiar, deixando de pagar alimentos e prestar aos filhos os cuidados e o afeto que necessitavam em fase do seu desenvolvimento. Negado provimento ao apelo. (Apelação Cívil n. 70013502331, TJRS, Relatora: Maria Berenice Dias).

Assim, não se trata de uma questão pacificada. Tal hipótese dá margem, quando se deixa de pensar em abandono material e se passa a pensar em abandono afetivo, ao

\footnotetext{
35 “O direito à prestação de alimentos é recíproco entre pais e filhos, e extensivo a todos os ascendentes, recaindo a obrigação nos mais próximos em grau, uns em falta de outros.”

${ }^{36}$ Cf. BRAGA, Pérola Melissa Vianna, op. cit., p. 17-18.

${ }^{37}$ Cf. DINIZ, Paula Fernanda, op. cit., p. 114.
} 


\section{REVI STA ELETRÔNI CA DA FACULDADE DE DI REITO DE FRANCA \\ www.revista.direitofranca.br \\ v. 7, n.1, jul/ 2013, ISSN: 1983-4225}

questionamento hipotético de se um idoso teria ou não direito de pleitear uma ação de abandono afetivo contra o filho se no passado tivesse abandonado afetivamente esse filho.

\subsection{DEVER DE ORDEM MORAL: O DEVER DE CUIDADO}

Segundo Tânia da Silva Pereira ${ }^{38}$, compõe a ideia de cuidado as atitudes oriundas da reciprocidade, entre as quais se destacam "o respeito, a atenção, o apoio, a compreensão, o afeto, a solidariedade e a proteção". No caso dos idosos, somam-se ainda o respeito e a tolerância. Trata-se de ações e atitudes dotadas de um caráter moral que não podem ser desprezadas pela sociedade, quiçá pelo ordenamento jurídico. Importante é a distinção entre os valores de cuidado e proteção:

\footnotetext{
Não se pode confundir cuidado com proteção. Cuidado pressupõe elementos subjetivos como carinho e afeto e estes só podem ser oferecidos pela família, sendo a de sangue, a escolhida e até amigos. Proteção tem significância objetiva e diz respeito aos direitos fundamentais cuja garantia de manutenção é obrigação primária e exclusiva do Estado. ${ }^{39}$
}

O cuidado, no âmbito das relações familiares passou a ser tratado como um valor jurídico através do reconhecimento do Superior Tribunal de Justiça na ocasião do julgamento do recurso especial n 1.159.242-SP ocorrido em abril de 2012. A Ministra Nancy Andrighi, relatora do voto, dispôs que “o cuidado como valor jurídico objetivo está incorporado no ordenamento jurídico brasileiro não com essa expressão, mas com locuções e termos que manifestam suas diversas desinências, como se observa do art. 227 da CF/88.”

Destarte, reconhecido o cuidado como um valor jurídico, quando perante o um filho comete perante seu pai idoso algum tipo de atitude como descaso, omissão ou negligencia ocorre uma violação do dever de cuidado.

Dessa forma, embora não se possa compelir alguém a amar, tornar o cuidado como um valor jurídico é um instrumento eficaz para se exigir maior atenção dos responsáveis pelo amparo daquelas pessoas mais vulneráveis do ordenamento, sob pena de responsabilização em virtude o descumprimento de tal dever.

Nesse sentido, a jurisprudência já expressa à importância do cuidado. Vejamos:

\footnotetext{
38 PEREIRA, Tânia da Silva. O cuidado como valor jurídico. Disponível em: <http://www.ibdfam.org.br/novosite/artigos/detalhe/216>. Acesso em 23 mar. 2013.

${ }^{39}$ BRAGA, Pérola Melissa Vianna, op. cit., p. 15.
} 


\title{
REVI STA ELETRÔNI CA DA FACULDADE DE DI REITO DE FRANCA \\ www.revista.direitofranca.br \\ v. 7, n.1, jul/ 2013, ISSN: 1983-4225
}

\begin{abstract}
Origem: TJDF - Tribunal de Justiça do Distrito Federal
Classe: AC- Apelação Cível

Processo: 2005/0110076865 UF: DF Órgão Julgador: QUINTA TURMA

Data da decisão: 24/04/2007

MANDADO DE SEGURANÇA- PRINCÍPIO DA EFETIVIDADE MÁXIMA DAS

NORMAS CONSTITUCIONAIS- PEDIDO DE REDUÇÃO DE CARGA

HORÁRIA, COM REDUÇÃO DE SALÁRIO, FORMULADO POR FILHO DE

PESSOA IDOSA OBJETIVANDO ASSISTIR-LHE DIANTE DA DOENÇA E

SOLIDÃO QUE O AFLINGEM- CUIDADOS ESPECIAIS QUE EXIGEM DEDICAÇÃO DO FILHO ZELOSO, ÚNICA PESSOA RESPONSÁVEL PELO GENITOR- DEVER DE AJUDA E AMPARO IMPOSTOS À FAMÍLIA, À SOCIEDADE, AO ESTADO E AOS FILHOS MAIORES- ORDEM CONCEDIDA
\end{abstract}

O Tribunal de Justiça do Distrito Federal, neste caso, deu procedente o pedido do autor, "único filho de um idoso doente, que buscava a redução da sua carga horária de trabalho, com consequente redução de salário, sob o argumento da necessidade de cuidar do genitor." 40 Tal caso, demonstra claramente como o dever de cuidado tem sido valorizado e reconhecido por nossos Tribunais além de usado para dar efetividade às normas constitucionais.

É importante destacar que a família não pode tirar, ainda que não intencionalmente, a autonomia e a liberdade de escolha do idoso, com o fundamento de poupá-lo. Trata-se de uma problemática que se apresenta quando o cuidado não é tomado na medida correta. Desta análise conclui-se que tanto a falta quanto o excesso de cuidado podem ferir a dignidade do idoso. E, o grande desafio é saber sopesar esse novo dever reconhecido pelo ordenamento jurídico de modo a garantir uma velhice amparada em cuidados e afeto, sem contudo ferir direitos personalíssimos. Isto porque, não é o fato de um idoso deter uma idade avançada que ele perde sua autonomia e capacidade. O idoso só perde sua capacidade caso houver um processo judicial de interdição, pois não existe presunção de incapacidade para os atos da vida civil.

\section{CONCLUSÃO}

O presente artigo, de modo geral, buscou demonstrar que a população idosa tem ganhado atenção da tutela jurídica em razão de sua fragilidade oriunda da idade bem como da discriminação que sofre por não fazer mais parte da parcela produtiva da população.

\footnotetext{
${ }^{40}$ FREITAS, JÚNIOR, Roberto Mendes, op. cit., p. 317.
} 


\section{REVI STA ELETRÔNI CA DA FACULDADE DE DI REITO DE FRANCA \\ www.revista.direitofranca.br \\ v. 7, n.1, jul/ 2013, ISSN: 1983-4225}

Diz o texto constitucional que a família tem o dever de amparar os idosos, destacando o papel dos filhos perante seus pais idosos. Por sua vez, o Estatuto do Idoso, tutela infraconstitucionalmente o comando constitucional, especificando o direito do idoso em diversos ramos do Direito. Já no âmbito do Direito de Família, o idoso pode contar com os deveres oriundos das relações de parentesco como o direito de receber de alimentos. No mais, o cuidado já é visto como um valor jurídico e o afeto é considerado princípio norteador do direito de família.

Assim, o envelhecimento da população brasileira desperta a importância do Direito para auxiliar na mudança de tratamento com os idosos, principalmente, do papel da doutrina e da jurisprudência como instrumentos para a efetivação dos direitos trabalhados nesta pesquisa.

\section{REFERÊNCIAS BIBLIOGRÁFICAS}

A ONU e as pessoas idosas. Disponível em: <http://www.onu.org.br/a-onu-em-acao/a-onuem-acao/a-onu-e-as-pessoas-idosas/>. Acesso em 27 mar. 2013.

ALCÂNTARA, Alexandre de Oliveira. O direito fundamental à velhice digna: limites e possibilidades de sua efetivação. 2007. 114f. Dissertação (Mestrado Direito) -Universidade de Fortaleza, Fortaleza, 2007.

BRAGA, Pérola Melissa Vianna. Curso de Direito do Idoso. São Paulo: Atlas, 2011.

Central do idoso divulga estatísticas de violência contra idosos no DF. Disponível em: $<$ http://www.tjdft.jus.br/institucional/imprensa/noticias/2012/setembro/central-do-idosodivulga-estatisticas-de-violencia-contra-idosos-no-df $>$. Acesso em 26 mar. 2013.

Conselho divulga dados da violência contra os idosos. Disponível em: $<$ http://www.sjdh.rs.gov.br/?model=conteudo\&menu=1\&id=285\&pg=>. Acesso em: 26 mar. 2013.

DIAS, Maria Berenice. Conversando sobre alimentos. Porto Alegra: Livraria do Advogado, 2006.

2011.

. Manual de Direito das famílias. 8. ed. São Paulo: Editora Revista dos Tribunais,

DINIZ, Paula Fernanda. Direitos dos idosos na perspectiva civil-constitucional. Belo Horizonte: Arraes, 2011.

FALEIROS, Vicente de Paula. Violência contra a pessoa idosa - ocorrências, vítimas e agressores. Brasília: Universa; 2007. p. 394 apud JUSSANA DE SOUSA, Danúbia et al . Maus-tratos contra idosos: atualização dos estudos brasileiros. Rev. Bras. Geriatr. Gerontol, 


\section{REVI STA ELETRÔNI CA DA \\ FACULDADE DE DI REITO DE FRANCA}

www.revista.direitofranca.br

v. 7, n.1, jul/ 2013, ISSN: 1983-4225

Rio de Janeiro, v. 13, n. 2, ago. 2010 . $\quad$ Disponível em

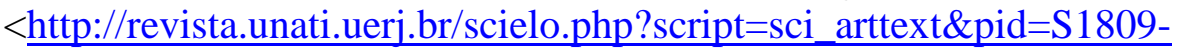
98232010000200016\&lng=pt\&nrm=iso>. Acessos em 26 mar. 2013.

FILHO, Wilson Jacob. Cuidar do idoso é desafio para a medicina do século 21. Ser médico, São Paulo, n. 61, p. 28-31, nov./dez. 2012.

FREITAS JÚNIOR, Roberto Mendes. Direitos e Garantias do Idoso: doutrina, jurisprudência e legislação. $2^{\circ}$ Ed. São Paulo: Atlas, 2011.

GAMA, Guilherme Calmon Nogueira da. Alimentos entre parentes e direito processual civil. In: MADALENO, Rolf; PEREIRA, Rodrigo da Cunha (Org.). Direito de família: processo, teoria e prática. Rio de Janeiro: Forense, 2008.

Pessoa idosa no direito de família. Disponível em: < http://civilistica.com/wpcontent/uploads/2013/01/Guilherme-Calmonciv.a2.n1.2013.pdf>. Acesso em: 20 mar. 2012.

INDALENCIO, Maristela Nascimento. Estatuto do Idoso e direitos fundamentais: fundamentos da proteção da pessoa idosa no ordenamento jurídico brasileiro. 2007. 114f. Dissertação (Mestrado em Ciência Jurídica) -Universidade do Vale do Itajaí, Itajaí, 2007.

JUSSANA DE SOUSA, Danúbia et al . Maus-tratos contra idosos: atualização dos estudos brasileiros. Rev. Bras. Geriatr. Gerontol., Rio de Janeiro, v. 13, n. 2, ago. 2010 . Disponível em:< $\quad$ http://revista.unati.uerj.br/scielo.php?script=sci_arttext\&pid=S180998232010000200016\&lng=pt\&nrm=iso> . Acessos em 26 mar. 2013.

OLIVEIRA, Maria Rita de Holanda Silva. Reflexos da constitucionalização nas relações de família. In: LOTUFO, Renan. Direito civil constitucional: caderno 3. São Paulo: Malheiros, 2002.

PEREIRA, Tânia da Silva. O cuidado como valor jurídico. Disponível em: < http://www.ibdfam.org.br/novosite/artigos/detalhe/216>. Acesso em 23 mar. 2013.

PERES, Ana Paula Ariston Barion. Proteção aos idosos. Curitiba: Juruá, 2011.

QUEIROZ, Clodoaldo de Oliveira. Os direitos fundamentais dos idosos. Revista de Direito Privado, São Paulo, v. 25, p. 89-122, jan./mar. 2006.

RAMOS, Paulo Roberto Barbosa. A velhice na Constituição. Disponível em: $<$ http://periodicos.ufsc.br/index.php/sequencia/article/view/15513/14069>. Acesso em: 03 abr. 2013.

RODRIGUES, Oswaldo Peregrina . A pessoa idosa e sua convivência em família. In:PEREIRA, Rodrigo da Cunha; PEREIRA, Tânia da Silva (Coord.). A ética da convivência familiar e sua efetividade no cotidiano dos tribunais. Rio de Janeiro: Forense, 2006. p. 395439. 